\title{
STRATEGI PENGEMBANGAN KOPERASI UNIT DESA (KUD) MINA TELUK SEMANGKA DI KECAMATAN KOTA AGUNG PUSAT KABUPATEN TANGGAMUS PROVINSI LAMPUNG
}

\author{
(Development Strategy of KUD Mina Teluk Semangka in Kota Agung Pusat Subdistrict \\ Tanggamus District of Lampung Province)
}

Anitha Andarrini T, Dyah Aring Hepiana Lestari, Indah Nurmayasari

\begin{abstract}
Jurusan Agribisnis, Fakultas Pertanian, Universitas Lampung, Jl. Prof. Dr. Soemantri Brojonegoro No.1
Bandar Lampung 35145, e-mail: dyah.aring@ fp.unila.ac.id
\end{abstract}

\begin{abstract}
This research aims to analyze the internal and external environment, formulate development strategies, and determine the priority strategies of KUD Mina Teluk Semangka. This research uses a case study method. Respondents involved 13 people consisting of administrators and members of cooperatives, experts and regulators. Data analysis methods used are qualitative descriptive analysis, SWOT analysis, and QSPM. The results indicated that internally, cooperatives have the main strength on its business units that are complement each other and suitable to the needs of members, while the main weakness is on the absence of processing.to add value of the products Externally, cooperatives face great opportunities on high level of demand on fish and face the main threat on lack of public awareness in working together. The priority strategies that can be used in developing cooperatives are as the following: utilizing and enhancing the ability of members to diversify their products using fishery product processing technology, collaborating with the government and other parties in creating tourism-based business unit, utilizing trained human resources to overcome limitations in keeping up with technological developments, and increasing awareness of the community in cooperation and members in paying mandatory savings.
\end{abstract}

Key words: cooperative, fisheries, SWOT analysis, QSPM

\section{PENDAHULUAN}

Struktur perekonomian Indonesia membagi kegiatan ekonomi menjadi tiga kelompok badan usaha yaitu BUMN (Badan Usaha Milik Negara), BUMS (Badan Usaha Milik Swasta) dan koperasi. Pemerintah mengharapkan ketiga kekuatan ekonomi tersebut dapat dikembangkan menjadi komponen-komponen yang saling mendukung di dalam sistem ekonomi sosial khususnya koperasi. Provinsi Lampung merupakan salah satu provinsi yang menjadikan koperasi sebagai sektor perekonomian.

Kabupaten Tanggamus adalah kabupaten yang memiliki jumlah koperasi cukup banyak di Provinsi Lampung yaitu 304 koperasi. Namun koperasi yang aktif terbilang rendah yaitu hanya 156 unit $(51,33 \%)$ serta sisanya 148 unit $(48,67 \%)$ dinyatakan pasif oleh Dinas Koperasi dan UKM Provinsi Lampung. Rendahnya koperasi aktif di Kabupaten Tanggamus antara lain disebabkan oleh adanya masalah dalam usaha koperasi, keterbatasan anggaran untuk memberikan pembinaan ataupun pelatihan perkoperasian dan sedikitnya strategi pengembangan dalam menjalankan usaha perkoperasian (Dinas Koperasi dan UMKM Kabupaten Tanggamus 2016).

Koperasi yang ada di Kabupaten Tanggamus terdiri dari berbagai jenis, salah satunya adalah koperasi perikanan. Koperasi Perikanan adalah koperasi yang anggotanya terdiri dari nelayan, peternak ikan, pemilik kolam ikan, pemilik alat perikanan dan sebagainya yang berkepentingan serta mata pencahariannya langsung berhubungan dengan usaha perikanan yang bersangkutan (Hadhikusuma 2002).

KUD Mina Teluk Semangka merupakan koperasi perikanan di Kabupaten Tanggamus yang berperan penting dalam perkembangan sektor perikanan. KUD Mina Teluk Semangka berkedudukan di pantai laut Kelurahan Pasar Madang Kabupaten Tanggamus dan mulai berdiri sejak tahun 1967 yang merupakan gabungan dari beberapa kelompok nelayan. Pada tanggal 10 Oktober 1995 resmi menjadi sebuah koperasi dengan Nomor Badan Hukum: 16/PAD/KWK/1995. KUD Mina Teluk Semangka bergerak dalam beberapa jenis usaha yang meliputi unit usaha tempat pelelangan ikan, es balok, simpan pinjam, solar packed dealer Nelayan dan waserda. 
KUD Mina Teluk Semangka masih menghadapi permasalahan dalam hal permodalan, usaha, organisasi, manajemen, dan lingkungan. Masalah yang dihadapi oleh KUD Mina Teluk Semangka yaitu kurangnya partisipasi anggota dalam mendukung koperasi melalui simpanan wajib dan simpanan sukarela yang mengakibatkan modal sendiri masih rendah, kurangnya inovasi atau pengembangan usaha, dan terdapat beberapa unit usaha yang tidak berjalan dengan baik. Unit-unit usaha tersebut belum dikembangkan secara optimal, padahal kawasan Teluk Semangka merupakan salah satu sentra perikanan di Kabupaten Tanggamus yang mempunyai potensi untuk dikembangkan. Banyak masyarakat yang berprofesi sebagai nelayan di lingkungan KUD Mina Teluk Semangka menghadapi berbagai masalah dalam melakukan aktivitas perikanan. Nelayan umumnya cukup terampil menggunakan peralatan yang dimiliki, tetapi seringkali sulit untuk ditingkatkan ke arah yang lebih moderen.

Posisi tawar nelayan sangat rendah karena modal yang terbatas, rendahnya produktivitas hasil tangkap yang tidak menentu akibat pengaruh musim serta jaminan pemasaran ikan yang tidak menentu akibat terdapatnya berbagai kendala dalam penentuan harga jual. Dalam membangun kemampuan nelayan untuk hal penyediaan sarana dan permodalan serta meningkatkan nilai tawar/posisi ekonomi, maka keberadaan koperasi perikanan sangat diperlukan oleh nelayan untuk mencapai taraf kehidupan yang lebih baik. Berdasarkan masalah tersebut, maka penelitian ini bertujuan untuk menganalisis lingkungan internal, menganalisis lingkungan eksternal dan, menyusun strategi pengembangan KUD Mina Teluk Semangka.

\section{METODE PENELITIAN}

Metode penelitian yang digunakan pada penelitian ini adalah studi kasus. Pelaksanaan penelitian berlokasi di KUD Mina Teluk Semangka Kecamatan Kota Agung Pusat Kabupaten Tanggamus Provinsi Lampung. Pemilihan lokasi dilakukan secara sengaja (purposive) dengan pertimbangan bahwa KUD Mina Teluk Semangka adalah koperasi perikanan tertua di Kabupaten Tanggamus dengan potensi usaha yang cukup baik.

Responden dalam penelitian ini dipilih menggunakan metode purposive sampling. Penelitian ini melibatkan sampel sebanyak 13 orang yang terdiri dari 3 orang pengurus koperasi, 1 orang pengawas, 6 orang anggota koperasi, 1 orang dosen Fakultas Pertanian Universitas Lampung, 1 orang perwakilan Dinas Koperasi, UMKM, dan Perindustrian Kabupaten Tanggamus, serta 1 orang perwakilan DKP (Dinas Kelautan dan Perikanan) Kabupaten Tanggamus.

Data yang digunakan dalam penelitian ini terdiri dari data primer dan data sekunder. Data primer diperoleh dari wawancara pengurus koperasi, anggota koperasi, pakar, dan pengambil kebijakan di Kabupaten Tanggamus dengan menggunakan kuesioner dan pengamatan serta pencatatan langsung tentang keadaan koperasi. Data sekunder diperoleh dari instansi terkait dan studi literatur.

\section{Analisis Lingkungan Internal}

Metode analisis data yang digunakan untuk menjawab tujuan pertama adalah analisis faktor lingkungan internal KUD Mina Teluk Semangka menggunakan matriks IFE (Internal Factor Evaluation) untuk memperoleh kekuatan yang dapat dimanfaatkan dan kelemahan yang harus diatasi. Faktor internal yang diidentifikasi meliputi komponen manajemen, permodalan dan keuangan, sumber daya manusia, unit usaha, sarana prasarana dan tertib administrasi.

\section{Analisis Lingkungan Eksternal}

Metode analisis data yang digunakan untuk menjawab tujuan ke dua adalah analisis faktor lingkungan eksternal KUD Mina Teluk Semangka menggunakan matriks EFE (Eksternal Factor Evaluation) untuk mengetahui peluang dan ancaman yang mempengaruhi KUD Mina Teluk Semangka. Faktor eksternal yang diidentifikasi meliputi komponen ekonomi, sosial dan budaya, kebijakan pemerintah, teknologi, pemasok, pesaing, serta iklim dan cuaca.

\section{Analisis Strategi Pengembangan}

Metode analisis data untuk menjawab tujuan ke tiga pada penelitian ini memiliki kesamaan dengan penelitian Purba, Affandi, dan Nugraha (2016) yaitu menggunakan analisis matriks IE dan analisis SWOT yang bertujuan untuk merumuskan alternatif strategi. Namun dalam menentukan strategi prioritas, pada penelitian ini tidak hanya menggunakan analisis SWOT, tetapi juga menggunakan matriks QSP. Analisis matriks QSP digunakan untuk mengetahui prioritas strategi dari hasil analisis SWOT. 
Matriks IE adalah matriks yang digunakan untuk mengetahui posisi KUD. Matriks IE didasarkan pada total nilai matriks IFE yang diberi bobot pada sumbu $\mathrm{X}$ dan total nilai matriks EFE yang diberi bobot pada sumbu Y. KUD ditempatkan pada matriks IE berdasarkan total skor pembobotan.

Jika berada pada sel I, II, atau IV maka KUD pada tahap tumbuh dan bangun (growth and build). Jika berada pada sel III, V, atau VII maka KUD pada tahap mempertahankan dan memelihara (hold and maintain). Jika berada pada sel VI, VIII, atau IX maka KUD pada tahap mengambil hasil atau melepaskan (harvest and divest). Matriks IE dapat dilihat pada Gambar 1. Analisis SWOT digunakan untuk mengidentifikasi faktor internal dan eksternal secara sistematis untuk merumuskan strategi pengembangan KUD Mina Teluk Semangka. Matriks SWOT menggambarkan peluang dan ancaman eksternal yang dihadapi KUD yang disesuaikan dengan kekuatan dan kelemahan internal yang dimiliki KUD. Matriks SWOT akan menghasilkan empat sel kemungkinan strategi.

Penyusunan strategi pengembangan pada penelitian melalui beberapa tahap. Tahap pertama, menentukan faktor-faktor lingkungan internal dan lingkungan eksternal. Tahap kedua, pemberian bobot dengan skala 1,0 (paling penting) sampai 0,0 (tidak penting) berdasarkan pengaruh faktor-faktor tersebut terhadap posisi strategis KUD. Tahap ketiga, menghitung rating dengan memberikan skala mulai dari 4 sampai dengan 1 dan tahap terakhir adalah mengalikan bobot dengan rating untuk menghasilkan skor pembobotan masingmasing faktor pada matriks IFE dan EFA.

\begin{tabular}{|c|c|c|c|c|}
\hline \multirow[b]{2}{*}{ THE EFAS } & \multicolumn{2}{|c|}{ THE IFAS } & \multicolumn{2}{|c|}{$\begin{array}{c}\text { TOTAL WEIGHTED } \\
\text { SCORES }\end{array}$} \\
\hline & & $\begin{array}{c}\text { Kuat } \\
3,0\end{array}$ & $\begin{array}{c}\text { Sedang } \\
2,0\end{array}$ & $\begin{array}{c}\text { Lemah } \\
1,0 \\
\end{array}$ \\
\hline \multirow{3}{*}{$\begin{array}{l}\text { TOTAL } \\
\text { WEIGHTED } \\
\text { SCORES }\end{array}$} & $\begin{array}{r}\text { Tinggi } \\
3,0\end{array}$ & I & II & III \\
\hline & $\begin{array}{r}\text { Sedang } \\
2,0\end{array}$ & IV & V & VI \\
\hline & $\begin{array}{r}\text { Rendah } \\
1,0\end{array}$ & VII & VIII & IX \\
\hline
\end{tabular}

Gambar 1. Matriks IE

Strategi yang terbentuk dari matriks SWOT kemudian disusun berdasarkan prioritas dengan menggunakan Quantitative Strategic Planning Matrix (QSPM). Mariks QSP digunakan untuk menentukan strategi prioritas KUD Mina Teluk Semangka dengan menentukan nilai daya tarik atau
Attractiveness Score (AS) dan total nilai daya tarik atau Total Attractiveness Score (TAS) strategi yang disesuaikan dengan faktor internal dan eksternal.

\section{HASIL DAN PEMBAHASAN}

\section{Karakteristik Responden}

Responden pengurus dan pengawas KUD Mina Teluk Semangka memiliki tingkat pendidikan menengah dan tinggi dengan rata-rata tingkat pendidikan yaitu SMA sebanyak tiga orang dan lulusan S1 sebanyak satu orang. Responden pengurus dan pengawas KUD Mina Teluk Semangka berada dalam kelompok umur produktif yaitu memiliki rentang umur antara 15 sampai 64 tahun.

Kemampuan pengurus KUD Mina Teluk Semangka dalam mengelola kegiatan koperasi didukung oleh tingkat pendidikan, pengalaman berkoperasi, dan pelatihan yang pernah diikuti. Sebagian besar pengurus sebelum bergabung dengan KUD Mina Teluk Semangka telah memiliki pengalaman berkoperasi di koperasi lain, sehingga pengurus sudah memiliki pengalaman dan pengetahuan mengenai perkoperasian. Selain itu juga, pengurus mengikuti pendidikan dan pelatihan seperti pendidikan dan pelatihan pengelolaan koperasi, diklat kader koperasi, pelatihan administrasi (pembukuan, neraca dan notulensi) serta kunjungan kerja atau studi banding ke koperasi lain.

Seluruh responden anggota KUD Mina Teluk Semangka juga memiliki tingkat pendidikan yang tinggi yaitu SMA dan termasuk dalam kelompok umur produktif karena berada pada rentang umur antara 15 sampai 64 tahun. Responden dari bidang akademik diwakili oleh dosen tetap di Jurusan Agribisnis Fakultas Pertanian Universitas Lampung. Beliau memiliki pengalaman dalam membina lembaga keuangan mikro Baitul Maal wat Tamwil (BMT) di Provinsi Lampung dan Pusat Inkubasi Bisnis Usaha Kecil (PINBUK) selama 25 tahun. Responden dari pihak pemerintah diwakili oleh kepala bidang koperasi pada Dinas Koperasi, UMKM dan Perindustrian Tanggamus dan kepala seksi bidang perikanan pada Dinas Perikanan dan Kelautan Tanggamus.

\section{Analisis Lingkungan Internal}

Hasil dari identifikasi lingkungan internal KUD Mina Teluk Semangka adalah 4 faktor kunci (key 
succes factors) untuk kekuatan dan 6 faktor kunci Pelaksanaan manajemen KUD Mina Teluk Semangka dilakukan secara demokratis yang didasarkan pada kesamaan hak suara bagi setiap anggota dalam pengelolaan koperasi baik dari fungsi perencanaan, pengorganisasian, pengarahan, dan pengawasan. KUD Mina Teluk Semangka memiliki permodalan dan keuangan yang mandiri, tetapi salah satu sumber modal berupa simpanan wajib tergolong rendah. Hal ini terjadi karena rendahnya kesadaran anggota untuk melunasi simpanan wajib. KUD Mina Teluk Semangka memiliki sumber daya manusia berupa pengurus dan anggota yang berpendidikan dan terlatih. Akan tetapi, keaktifan dan pelatihan yang diterima anggota belum optimal.

KUD Mina Teluk Semangka memiliki lima unit usaha. Tiga unit usaha saling melengkapi dan sesuai dengan kebutuhan anggota. Namun, dua unit usaha belum berjalan dengan baik dan belum memiliki unit usaha pengolahan produk yang menghasilkan nilai tambah. Sarana dan prasarana yang dimiliki KUD Mina Teluk Semangka menjadi kelemahan koperasi karena umur ekonomis sarana dan prasarana koperasi terbilang rendah.

Penerapan tertib administrasi di KUD Mina Teluk Semangka terkait dengan buku-buku administrasi berupa buku daftar anggota, daftar simpanan anggota, daftar pengurus, notulen rapat anggota, daftar inventaris koperasi, administrasi transaksi usaha koperasi dengan anggota, dan akuntansi koperasi sudah dikelola dengan baik oleh pengurus. Namun keberadaan buku-buku administrasi terpisah tidak pada satu tempat. Hal ini menjadi kelemahan bagi KUD Mina Teluk (key succes factors) untuk kelemahan. Semangka karena saat buku-buku tersebut dibutuhkan dengan cepat buku-buku tersebut tidak tersedia. Matriks IFE KUD Mina Teluk Semangka dapat dilihat pada Tabel 1.

Faktor kekuatan paling penting berupa unit usaha yang saling melengkapi dan sesuai dengan kebutuhan anggota memiliki bobot 0,141 dengan nilai rating 4 sehingga menghasilkan skor 0,564. Skor tertinggi pada faktor ini menunjukkan bahwa unit usaha yang dikelola KUD Mina Teluk Semangka berupa unit usaha SPDN, unit usaha tempat pelelangan ikan, dan unit usaha es balok saling melengkapi dan sesuai kebutuhan anggota memiliki pengaruh yang sangat kuat dalam pengembangan KUD Mina Teluk Semangka. Hal tersebut menjadi kekuatan utama karena, unit usaha yang ada mendukung keadaan dan perekonomian masyarakat sekitar Teluk Semangka kabupaten Tanggamus sehingga berdampak pula pada perolehan pendapatan dan keberhasilan KUD Mina Teluk Semangka.

Faktor kelemahan paling penting berupa belum adanya pengolahan produk yang menghasilkan nilai tambah memiliki bobot 0,085 dengan nilai rating 3 sehingga menghasilkan skor 0,254. Skor tertinggi pada faktor ini menunjukkan bahwa pengolahan produk yang menghasilkan nilai tambah sangat diperlukan KUD Mina Teluk Semangka untuk memanfaatkan hasil perikanan tangkap seoptimal mungkin dengan melakukan pengolahan hasil ikan tangkap lebih lanjut sehingga dapat meningkatkan perolehan pendapatan.

Tabel 1. Matriks IFE KUD Mina Teluk Semangka

\begin{tabular}{|c|c|c|c|c|}
\hline Faktor Internal & Bobot & Rating & Skor $(\mathrm{BxR})$ & Rangking \\
\hline \multicolumn{5}{|l|}{ Kekuatan } \\
\hline $\begin{array}{l}\text { A Pelaksanaan manajemen KUD Mina Teluk Semangka dilakukan secara } \\
\text { demokratis }\end{array}$ & 0,114 & 3 & 0,341 & 4 \\
\hline B Permodalan dan keuangan yang mandiri & 0,134 & 3 & 0,403 & 3 \\
\hline C Sumber daya manusia yang berpendidikan dan terlatih & 0,138 & 3 & 0,413 & 2 \\
\hline $\begin{array}{l}\text { D Unit usaha yang saling melengkapi dan sesuai dengan kebutuhan } \\
\text { anggota }\end{array}$ & 0,141 & 4 & 0,564 & 1 \\
\hline \multicolumn{5}{|l|}{ Kelemahan } \\
\hline E Rendahnya kesadaran anggota untuk melunasi simpanan wajib & 0,079 & 3 & 0,236 & 3 \\
\hline F Keaktifan dan pelatihan yang diterima anggota belum optimal & 0,083 & 3 & 0,249 & 2 \\
\hline G Adanya beberapa unit usaha yang belum berjalan dengan baik & 0,079 & 2 & 0,157 & 4 \\
\hline H Belum adanya pengolahan produk yang menghasilkan nilai tambah & 0,085 & 3 & 0,254 & 1 \\
\hline I Umur ekonomis sarana dan prasarana koperasi rendah & 0,079 & 2 & 0,157 & 5 \\
\hline J Keberadaan buku administrasi KUD Mina Teluk Semangka terpisah & 0,071 & 2 & 0,142 & 6 \\
\hline Total Nilai IFE & 1,00 & & 2,913 & \\
\hline
\end{tabular}




\section{Analisis Lingkungan Eksternal}

Hasil dari identifikasi lingkungan Eksternal koperasi adalah 6 faktor kunci (key succes factors) untuk peluang dan 4 faktor kunci (key succes factors) untuk ancaman. Menurut DKP Kabupaten Tanggamus (2018) produksi perikanan tangkap di perairan laut Tanggamus terbilang cukup tinggi mencapai 10.066 ton per tahun. Tingginya produksi perikanan tangkap juga disertai dengan tingginya tingkat permintaan dan konsumsi produk perikanan tangkap di Kabupaten Tanggamus. Tingkat permintaan dan konsumsi produk perikanan tangkap yang tinggi menjadi peluang bagi KUD Mina Teluk Semangka dalam meningkatkan pendapatan dan kesejahteraan nelayan anggota. Selain itu, lokasi unit usaha KUD Mina Teluk Semangka yang berdekatan dengan kawasan wisata menjadi peluang bagi koperasi. Kebijakan pemerintah untuk mengadakan pelatihan dan pembinaan bagi pengurus/karyawan dan anggota serta adanya dukungan dan bantuan dari pemerintah merupakan peluang yang dapat dimanfaatkan oleh KUD Mina Teluk Semangka.

KUD Mina Teluk Semangka telah menggunakan teknologi produksi yang lebih moderen. Hal ini menjadi peluang bagi KUD Mina Teluk Semangka. Nelayan anggota merupakan pemasok tetap bagi unit usaha TPI KUD Mina Teluk Semangka. Keberadaan pemasok tetap menjadi peluang bagi KUD Mina Teluk Semangka terhadap keberlangsungan unit usaha TPI. Sebagian masyarakat di lingkungan KUD Mina Teluk Semangka masih sulit untuk diajak berusaha dalam koperasi karena kurangnya kesadaran masyarakat dalam berkoperasi. Pada KUD Mina Teluk Semangka dalam penggunaan teknologi informasi dan produksi mengalami keterbatasan dalam mengikuti perkembangan teknologi dan terdapat pesaing usaha sejenis yang berpengaruh terhadap KUD Mina Teluk Semangka. Perubahan kondisi alam di perairan tanggamus tidak menentu. Iklim dan cuaca yang tidak stabil mengakibatkan tingkat produktivitas perolehan ikan KUD Mina Teluk Semangka menurun. Keempat hal ini merupakan faktor eksternal ancaman bagi KUD Mina Teluk Semangka dalam menjalankan usahanya. Matriks EFE KUD Mina Teluk Semangka dapat dilihat pada Tabel 2.

Faktor peluang utama berupa tingginya tingkat permintaan atau konsumsi perikanan tangkap memiliki bobot 0,127 dengan nilai rating 4 sehingga diperoleh skor 0,510 . Skor tertinggi pada faktor ini menunjukkan bahwa tingkat permintaan atau konsumsi perikanan tangkap yang tinggi berpengaruh sangat kuat dalam pengembangan KUD Mina Teluk Semangka, terutama dalam hal efisiensi pemasaran hasil perikanan tangkap sehingga perolehan pendapatan koperasi tinggi dan dapat memajukan seluruh unit usaha yang ada.

Faktor ancaman paling penting berupa kurangnya kesadaran masyarakat dalam berkoperasi memiliki bobot 0,091 dengan nilai rating 3.sehingga menghasilkan skor 0,272. Skor tertinggi pada faktor ini menunjukkan bahwa kurangnya kesadaran masyarakat dalam berkoperasi menjadi suatu ancaman terbesar yang dihadapi KUD Mina Teluk Semangka karena, masyarakat memiliki kemauan dan kesadaran yang rendah terhadap aktifitas koperasi.

Tabel 2. Matriks EFE KUD Mina Teluk Semangka

\begin{tabular}{lcccc}
\hline \multicolumn{1}{c}{ Faktor Eksternal } & Bobot & Rating & Skor (BxR) & Rangking \\
\hline Peluang & & & & \\
\hline A Tingginya tingkat permintaan/konsumsi perikanan tangkap & 0,127 & 4 & 0,510 & 1 \\
B Kebijakan pemerintah untuk mengadakan pelatihan dan pembinaan bagi & 0,112 & 3 & 0,336 & 4 \\
pengurus/karyawan dan anggota & & & \\
C Adanya dukungan dan bantuan dari pemerintah & 0,080 & 3 & 0,241 & 6 \\
D Penggunaan teknologi yang lebih moderen & 0,130 & 3 & 0,390 & 2 \\
E Lokasi usaha berada dekat dengan kawasan wisata. & 0,080 & 4 & 0,321 & 5 \\
F Adanya pemasok tetap yang menjamin keberlangsungan unit usaha TPI & 0,127 & 3 & 0,380 & 3 \\
$\quad$ KUD Mina Teluk Semangka & & & & \\
\hline Ancaman & 0,091 & 3 & 0,272 & 1 \\
\hline G Kurangnya kesadaran masyarakat dalam berkoperasi & 0,112 & 2 & 0,224 & 2 \\
H Keterbatasan dalam mengikuti perkembangan teknologi & 0,081 & 2 & 0,162 & 3 \\
I Keberadaan pesaing sejenis berpengaruh terhadap KUD Mina Teluk & 0,060 & 2 & 0,120 & 4 \\
J Semangka & & & & \\
$\quad$ Ketidakstabilan iklim dan cuaca & 1,000 & & 2,955 & \\
\hline$\quad$ Total Nilai IFE & &
\end{tabular}


Sebagian besar masyarakat di lingkungan KUD Mina Teluk Semangka tidak menjadi anggota koperasi hal ini karena, masyarakat kurang mempercayai koperasi sehingga koperasi dinilai kurang menarik untuk dijadikan suatu usaha bersama.

\section{Strategi Pengembangan}

Berdasarkan hasil analisis faktor internal dan eksternal KUD Mina Teluk Semangka menggunakan matriks IFE dan EFE dihasilkan matriks I-E yang disajikan pada Gambar 2 dan SWOT. Matriks I-E digunakan untuk mengetahui posisi KUD Mina Teluk Semangka, sedangkan analisis SWOT digunakan untuk mengevaluasi kekuatan, kelemahan, peluang, dan ancaman yang dimiliki dan dihadapi KUD Mina Teluk Semangka. Selanjutnya, analisis SWOT tersebut menghasilkan alternatif strategi dan matriks QSP yang disajikan pada Tabel 4 guna mengetahui prioritas strategi pengembangan KUD Mina Teluk Semangka.

\section{Matriks Internal Eksternal (IE)}

Matriks I-E adalah perpaduan dari skor terbobot matriks IFE dan skor terbobot matriks EFE guna mengetahui posisi usaha yang sedang dijalankan. Berdasarkan hasil analisis faktor internal menggunakan matriks IFE diperoleh bobot skor sebesar 2,913 dan hasil analisis faktor eksternal menggunakan matriks EFE diperoleh bobot skor sebesar 2,955 menunjukkan bahwa posisi internal maupun eksternal KUD Mina Teluk Semangka bernilai sedang atau rata-rata. Matriks IE KUD Mina Teluk Semangka pada Gambar 2 menunjukkan bahwa KUD Mina Teluk Semangka berada pada sel strategi V. Strategi yang dapat diterapkan pada sel strategi $\mathrm{V}$ adalah menjaga dan mempertahankan (bold and maintain). Strategi yang banyak digunakan pada sel ini adalah pengembangan produk dan penetrasi pasar.

Hasil yang serupa terdapat pada penelitian Irawati, Hubeis, dan Muksin (2017) mengenai Strategi Pengembangan Koperasi Peternak Galur Murni Di Kabupaten Jember yang menghasilkan matriks I-E pada posisi sel V. Artinya posisi koperasi berada dalam kondisi internal rata-rata dan respon terhadap faktor eksternal yang dihadapi tergolong menengah sehingga alternatif strategi yang digunakan adalah pengembangan produk dan penetrasi pasar.

\begin{tabular}{|c|c|c|c|c|}
\hline \multirow[b]{2}{*}{ THE EFAS } & \multicolumn{2}{|c|}{ THE IFAS } & \multicolumn{2}{|c|}{$\begin{array}{c}\text { TOTAL WEIGHTED } \\
\text { SCORES }\end{array}$} \\
\hline & & $\begin{array}{c}\text { Kuat } \\
3,0\end{array}$ & $\begin{array}{c}\text { Sedang } \\
2,0\end{array}$ & $\begin{array}{c}\text { Lemah } \\
1,0\end{array}$ \\
\hline \multirow{3}{*}{$\begin{array}{l}\text { TOTAL } \\
\text { WEIGHTED } \\
\text { SCORES }\end{array}$} & $\begin{array}{r}\text { Tinggi } \\
3,0\end{array}$ & I & II & III \\
\hline & $\begin{array}{r}\text { Sedang } \\
2,0\end{array}$ & $\overline{\mathbf{I V}}-$ & V & VI \\
\hline & $\begin{array}{r}\text { Rendah } \\
1,0\end{array}$ & VII & VIII & IX \\
\hline
\end{tabular}

Gambar 2. Matriks I-E KUD Mina Teluk Semangka

\section{Matriks SWOT}

Analisis matriks SWOT KUD Mina Teluk Semangka menghasilkan 15 alternatif strategi yaitu

a. Strategi SO KUD Mina Teluk Semangka sebagai berikut :

1) Mengelola manajemen keanggotaan koperasi guna mendukung keberhasilan pemerintah dalam mengadakan pelatihan dan pembinaan bagi KUD Mina Teluk Semangka.

2) Menggunakan permodalan dan keuangan yang mandiri secara efektif untuk mengembangkan teknologi yang lebih moderen.

3) Kerja sama dengan pemerintah dan pihak lain dalam menciptakan pengembangan unit usaha berbasis wisata.

4) Memanfaatkan dukungan dan bantuan dari pemerintah untuk mengoptimalkan unit usaha yang ada agar dapat saling melengkapi.

b. Strategi WO KUD Mina Teluk Semangka sebagai berikut :

1) Meningkatkan partisipasi dan kesadaran anggota dalam memajukan unit usaha KUD Mina Teluk Semangka.

2) Memaksimalkan pengelolaan manajemen dalam pelaksanaan tertib administrasi sehingga manajemen koperasi lebih tertata.

3) Memanfaatkan teknologi yang lebih moderen untuk mengoptimalkan jalannya unit usaha.

4) Mendayagunakan dan meningkatkan kemampuan anggota dalam diversifikasi produk dengan menggunakan teknologi pengolahan hasil perikanan tangkap.

5) Menggunakan bantuan pemerintah secara efisien guna memperbaiki sarana dan prasarana. 
c. Strategi ST KUD Mina Teluk Semangka sebagai berikut :

1) Memanfaatkan sumber daya manusia yang terlatih untuk mengatasi keterbatasan dalam mengikuti perkembangan teknologi.

2) Memanfaatkan SDM yang berpendidikan dan terlatih guna mengatasi risiko ketidakstabilan iklim dan cuaca.

3) Mengoptimalkan pendapatan unit usaha yang saling melengkapi dengan menggunakan teknologi serta meningkatkan kesadaran masyarakat dalam berkoperasi.

d. Strategi WT KUD Mina Teluk Semangka sebagai berikut :

1) Meningkatkan kesadaran masyarakat dalam berkoperasi dan anggota dalam melunasi simpanan wajib untuk dapat meningkatkan modal KUD Mina Teluk Semangka.

2) Meningkatkan ketrampilan anggota KUD Mina Teluk Semangka untuk mengatasi persaingan yang ada.

3) Menghasilkan diversifikasi produk dari hasil perikanan untuk mengatasi persaingan yang ada.

\section{Matriks QSP}

Matriks QSP digunakan untuk menetapkan strategi prioritas dari ke 15 alternatif strategi yang dihasilkan matriks SWOT secara objektif. Berdasarkan matriks QSP pada Tabel 3 diperoleh empat strategi prioritas utama yang memiliki skor penilaian tertinggi sebagai berikut:

1. Mendayagunakan dan meningkatkan kemampuan anggota dalam diversifikasi produk dengan menggunakan teknologi pengolahan hasil perikanan tangkap. KUD Mina Teluk Semangka dapat menambah unit usaha pengolahan ikan untuk menghasilkan diversifikasi olahan ikan berupa abon ikan, kerupuk ikan, dan ikan asap dengan menggunakan teknologi produksi pengolahan ikan. Strategi prioritas pada penelitian ini memiliki persamaan dengan penelitian Ghaisani (2017) yaitu meningkatkan kualitas produk dan variasi produk yang dihasilkan dengan memanfaatkan penggunaan teknologi produksi, informasi, dan komunikasi.
2. Kerja sama dengan pemerintah dan pihak lain dalam menciptakan pengembangan unit usaha berbasis wisata. Lokasi usaha KUD Mina Teluk Semangka berdekatan dengan kawasan wisata pantai Muara Indah sehingga dapat dilakukan pengembangan unit usaha berbasis wisata bahari. Strategi prioritas dalam penelitian ini sejalan dengan penelitian Nurhidayati, Lestari, dan Nugraha (2015) yaitu bekerja sama dengan pihak lain dalam membantu mengarahkan dan mengikuti perkembangan teknologi yang moderen.

3. Memanfaatkan sumber daya manusia yang terlatih untuk mengatasi keterbatasan dalam mengikuti perkembangan teknologi. Keterkaitan antara sumber daya manusia yang berpendidikan dan terlatih dengan teknologi sangatlah erat sehingga dibutuhkan sumber daya manusia yang kompeten dan mampu menguasai teknologi agar KUD Mina Teluk Semangka dapat berjalan dengan baik. Strategi prioritas pada penelitian ini memiliki kesamaan dengan penelitian Putri, Lestari, dan Sayekti (2017) yaitu memanfaatkan sumber daya manusia yang terlatih untuk mengatasi keterbatasan dalam mengikuti perkembangan teknologi.

4. Meningkatkan kesadaran masyarakat dalam berkoperasi dan kesadaran anggota dalam melunasi simpanan wajib agar dapat meningkatkan modal KUD Mina Teluk. Semangka. Untuk meningkatkan kesadaran masyarakat untuk berkoperasi KUD Mina Teluk Semangka perlu meningkatkan sosialisasi berkoperasi agar masyarakat dapat mengetahui manfaat dari berpartisipasi aktif dalam koperasi. KUD Mina Teluk Semangka berupaya mengoptimalkan pelunasan simpanan wajib agar anggaran kegiatan koperasi dan perputaran modal unit usaha dapat berjalan optimal sehingga KUD Mina Teluk Semangka mudah berkembang. Strategi prioritas pada penelitian ini memiliki kesamaan dengan penelitian Pratama, Hubeis, dan Pandjaitan (2017) dan penelitian Putri et al. (2017) yaitu meningkatkan sosialisasi berkoperasi kepada masyarakat sekitar guna membentuk citra positif koperasi dan meningkatkan kesadaran anggota untuk melunasi simpanan wajib untuk dapat meningkatkan modal serta bekerja sama dengan pemasok. 
Tabel 3. Strategi prioritas KUD Mina Teluk Semangka Kabupaten Tanggamus menurut QSPM

\begin{tabular}{lcc}
\hline \multicolumn{1}{c}{ Alternatif Strategi } & Total Skor & Ranking \\
\hline $\begin{array}{l}\text { Mendayagunakan dan meningkatkan kemampuan anggota dalam diversifikasi produk } \\
\text { dengan menggunakan teknologi pengolahan hasil perikanan tangkap }\end{array}$ & 5,751 & 1 \\
$\begin{array}{l}\text { Kerja sama dengan pemerintah dan pihak lain dalam menciptakan pengembangan unit } \\
\text { usaha berbasis wisata }\end{array}$ & 5,403 & 2 \\
$\begin{array}{l}\text { Memanfaatkan sumber daya manusia yang terlatih untuk mengatasi keterbatasan dalam } \\
\text { mengikuti perkembangan teknologi }\end{array}$ & 5,266 & 3 \\
$\begin{array}{l}\text { Meningkatkan kesadaran masyarakat dalam berkoperasi dan kesadaran anggota dalam } \\
\text { melunasi simpanan wajib agar dapat meningkatkan modal KUD Mina Teluk Semangka }\end{array}$ & 5,216 & 4 \\
\hline
\end{tabular}

\section{KESIMPULAN}

KUD Mina Teluk Semangka, secara internal memiliki kekuatan utama berupa unit usaha saling melengkapi yang sesuai dengan kebutuhan anggota dan kelemahan utama berupa belum adanya pengolahan produk yang menghasilkan nilai tambah. Secara eksternal, peluang utama yang dimiliki berupa tingginya tingkat permintaan atau konsumsi perikanan tangkap dan ancaman utama berupa kurangnya kesadaran masyarakat dalam berkoperasi. Strategi prioritas yang dapat digunakan untuk pengembangan KUD Mina Teluk Semangka adalah mendayagunakan dan meningkatkan kemampuan anggota dalam diversifikasi produk dengan menggunakan teknologi pengolahan hasil perikanan tangkap, kerja sama dengan pemerintah dan pihak lain dalam menciptakan pengembangan unit usaha berbasis wisata, memanfaatkan sumberdaya manusia yang terlatih untuk mengatasi keterbatasan dalam mengikuti perkembangan teknologi, serta meningkatkan kesadaran masyarakat dalam berkoperasi dan anggota dalam melunasi simpanan wajib agar dapat meningkatkan modal KUD Mina Teluk Semangka.

\section{DAFTAR PUSTAKA}

David FR. 2009. Manajemen Strategi: Konsep, Buku satu. Edisi ke-12. Terjemahan Ichsan, Setyo Budi. Salemba Empat. Jakarta.

DKP [Dinas Kelautan dan Perikanan] Kabupaten Tanggamus. 2018. Produksi kelautan dan perikanan tangkap Kabupaten Tanggamus tahun 2013-2017. DKP Kabupaten Tanggamus. Kota Agung.

Dinas Koperasi dan UMKM Kabupaten Tanggamus. 2016. Sebaran koperasi menurut sector di Kabupaten Tanggamus Tahun 2016.
Dinas Koperasi dan UMKM Kabupaten Tanggamus. Kota Agung.

Ghaisani AS. 2017. Analisis Kinerja dan Strategi Pengembangan Usaha Tani Sayuran Organik di Kota Bandar Lampung. Skripsi. Universitas Lampung. Bandar Lampung.

Hadhikusuma. SR. 2002. Hukum Koperasi Indonesia. Rajawali Pers. Jakarta.

Irawati DA, Hubeis M, dan Muksin. 2017. Strategi pengembangan Koperasi Peternak Galur Murni di Kabupaten Jember. Jurnal Aplikasi Bisnis dan Manajemen, 3(1): 123130. http://journal.ipb.ac.id/index.php/jabm /article/view/14879. [25 Desember 2017].

Nurhidayati E, Lestari DAH, dan Nugraha A. 2015. Strategi pengembangan Koperasi Agro Siger Mandiri di Kecamatan Kalianda Kabupaten Lampung Selatan. JIIA, 3(1): 5765. http://jurnal.fp.unila.ac.id/index.php/ JIA/ article/view/1018/923. [25 Desember 2017].

Pratama L, Hubeis AVS, dan Pandjaitan NH. 2017. Analisis tingkat kepuasan anggota dan strategi pengembangan koperasi (Studi Kasus Koperasi Kredit Sehati Jakarta). Jurnal Manajemen IKM, 12(1): 104-115. http://journal.ipb.ac.id/index.php/jurnalmpi/art icle/view/17996. [25 Desember 2017].

Purba MN, Affandi MI, dan Nugraha A. 2016. Strategi pengembangan Kopdit Mekar Sai dalam pembiayaan agribisnis di Lampung. JIIA, 4(3): 285-293. http://jurnal. fp.unila.ac.id/index.php/JIA/article/view/1503 /1357. [25 Desember 2017].

Putri RM, Lestari DAH, dan Sayekti WS. 2017. Kinerja dan strategi pengembangan PRIMKOPTI Kabupaten Pesawaran Provinsi Lampung. JIIA, 5(2): 184-191. http://jurnal.fp.unila.ac.id/index.php/JIA/articl e/ view/1657/1483. [25 Desember 2017]. 